\title{
Comparison of UV irradiances from Aura/Ozone Monitoring Instrument (OMI) with Brewer measurements at EI Arenosillo (Spain) - Part 2: Analysis of site aerosol influence
}

\author{
V. E. Cachorro ${ }^{1}$, C. Toledano ${ }^{1}$, M. Antón ${ }^{2, *}$, A. Berjón ${ }^{1}$, A. de Frutos $^{1}$, J. M. Vilaplana ${ }^{3}$, A. Arola ${ }^{4}$, and \\ N. A. Krotkov ${ }^{5,6}$ \\ ${ }^{1}$ Grupo de Óptica Atmosférica, Universidad de Valladolid GOA-UVA, Valladolid, Spain \\ ${ }^{2}$ Departamento de Física, Universidad de Extremadura, Badajoz, Spain \\ ${ }^{3}$ ESAt "El Arenosillo", INTA, Huelva, Spain \\ ${ }^{4}$ Finnish Meteorological Institute (FMI), Kuopio, Finland \\ ${ }^{5}$ GEST Center, University of Maryland, Baltimore County, Maryland, USA \\ ${ }^{6}$ Laboratory of Atmosphere, NASA/Goddard Space Flight Center, Greenbelt, Maryland, USA \\ * now at: Departamento de Física Aplicada, Universidad de Granada, Granada, Spain
}

Received: 21 April 2010 - Published in Atmos. Chem. Phys. Discuss.: 1 July 2010

Revised: 24 November 2010 - Accepted: 25 November 2010 - Published: 13 December 2010

\begin{abstract}
Several validation studies have shown a notable overestimation of the clear sky ultraviolet (UV) irradiance at the Earth's surface derived from satellite sensors such as the Total Ozone Mapping Spectrometer (TOMS) and the Ozone Monitoring Instrument (OMI) with respect to groundbased UV data at many locations. Most of this positive bias is attributed to boundary layer aerosol absorption that is not accounted for in the TOMS/OMI operational UV algorithm. Therefore, the main objective of this study is to analyse the aerosol effect on the bias between OMI erythemal UV irradiance (UVER) and spectral UV (305 nm, $310 \mathrm{~nm}$ and $324 \mathrm{~nm}$ ) surface irradiances and ground-based Brewer spectroradiometer measurements from October 2004 to December 2008 at El Arenosillo station $\left(37.1^{\circ} \mathrm{N}, 6.7^{\circ} \mathrm{W}\right.$, $20 \mathrm{~m}$ a.s.l.), with meteorological conditions representative of the South-West of Spain.

The effects of other factors as clouds, ozone and the solar elevation over this intercomparison were analysed in detail in a companion paper (Antón et al., 2010). In that paper the aerosol effects were studied making only a rough evaluation based on aerosol optical depth (AOD) information at $440 \mathrm{~nm}$ wavelength (visible range) without applying any correction. We have used the precise information given by single scattering albedo (SSA) from AERONET for the determination of
\end{abstract}

absorbing aerosols which has allowed the correction of the OMI UV data.

An aerosol correction expression was applied to the OMI operational UV data using two approaches to estimate the UV absorption aerosol optical depth, AAOD. The first approach was based on an assumption of constant SSA value of 0.91 . This approach reduces the OMI UVER bias against the reference Brewer data from $13.4 \%$ to $8.4 \%$. Second approach uses daily AERONET SSA values reducing the bias only to $11.6 \%$. Therefore we have obtained a $37 \%$ and $12 \%$ of improvement respectively. For the spectral irradiance at $324 \mathrm{~nm}$, the OMI bias is reduced from $10.5 \%$ to $6.98 \%$ for constant SSA and to $9.03 \%$ for variable SSA. Similar results were obtained for spectral irradiances at $305 \mathrm{~nm}$, and $310 \mathrm{~nm}$.

Contrary to what was expected, the constant SSA approach has a greater bias reduction than variable SSA, but this is a reasonable result according to the discussion about the reliability of SSA values. Our results reflect the level of accuracy that may be reached at the present time in this type of comparison, which may be considered as satisfactory taking into account the remaining dependence on other factors. Nevertheless, improvements must be accomplished to determine reliable absorbing aerosol properties, which appear as a limiting factor for improving OMI retrievals.

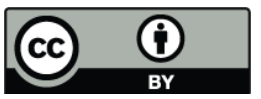

Correspondence to: V. E. Cachorro

(chiqui@goa.uva.es)

Published by Copernicus Publications on behalf of the European Geosciences Union. 


\section{Introduction}

It is well established by several validation works (Arola et al., 2005; Antón et al., 2007; Kazantzidis et al., 2006, 2009; Arola et al., 2009) that UV irradiance at the ground given by satellite instruments such as TOMS (Total Ozone Mapping Spectrometer) and OMI (Ozone Monitoring Instrument) (Krotkov et al., 2002) is overestimated compared with ground based UV measurements at many polluted locations. This positive (satellite overestimation) clear-sky bias varies widely depending on the climatological conditions at validation sites. Most of this positive bias is attributed to boundary layer aerosol absorption. TOMS UV algorithm has an Aerosol Index-based correction for the absorbing aerosol which is not included in the current version of OMI UV algorithm (Krotkov et al., 2005; Arola et al., 2009).

The OMI instrument is a Dutch-Finnish push-broom UVVisible spectrometer, a contribution to NASA-EOS/Aura mission, launched in July 2004. It is the successor of the long-lived NASA-TOMS programme (onboard different platforms: Nimbus-7, Meteo-3 and Earth-Probe) which began at the end of the 1970's years to measure atmospheric composition. First validation of OMI UV data can be found in the work of Tanskanen et al. (2007). The validation results showed a good agreement between OMI-derived daily erythemal doses and the daily doses calculated from the groundbased spectral UV measurements from 18 reference instruments (stations in Europe, Canada, Japan, USA and Antarctic). However, a positive OMI bias up to $\sim 50 \%$ was found for polluted sites significantly affected by absorbing aerosols or trace gases.

Recent publications on OMI operational UV validation have been carried out by Buchard et al. (2008), Ialongo et al. (2008) and Weihs et al. (2008) at different European locations but no aerosol corrections were made. More recently, the works of Kazadzis et al. (2009), Arola et al. (2009) and Ialongo et al. (2010) have applied the aerosol absorption correction suggested earlier in Krotkov et al. (2005) and Arola et al. (2005). The first work applies the correction based on local aerosol in the urban location of Thessaloniki (Greece), showing that the OMI instrument overestimates UV spectral irradiances at $305 \mathrm{~nm}, 324 \mathrm{~nm}$, and $380 \mathrm{~nm}$ by $30 \%, 17 \%$ and $13 \%$, respectively. In the paper of Arola et al. (2009) the correction is based on a global climatology of aerosols, using combined information of aerosol models and AERONET data. This work has been carried out over seven European sites (including El Arenosillo station) and showed a reduction of the bias from $22 \%$ to $17 \%$ for the UV spectral irradiance at $324 \mathrm{~nm}$ under different atmospheric conditions. Ialongo et al. (2010) following a methodology very similar to that of Kazadzis et al. (2009) for the retrieval of the single scattering albedo (SSA) and the absorption aerosol optical depth (AAOD, based on the comparison of measured spectra by Brewer and modeled data) obtains a strong bias reduction for spectral OMI irradiances at $324.5 \mathrm{~nm}$ (from 18\% to 2\%) and also for erythemal dose rates (from $25 \%$ to $8 \%$ ) in the Rome urban site.

In this framework, our work is focused on the comparison between OMI UV irradiance products (erythemal irradiance (UVER), and spectral irradiances at 305, 310 and $324 \mathrm{~nm}$ ) and the ground-based UV measurements using a well-calibrated Brewer spectroradiometer located at El Arenosillo $\left(37.1^{\circ} \mathrm{N}, 6.7^{\circ} \mathrm{W}, 20 \mathrm{~m}\right.$ a.s.1.), representative of the SW of Spain. In a companion paper (Antón et al., 2010) the effect of several factors as clouds, aerosols, ozone and the solar elevation on OMI-Brewer UV bias were analysed and compared with previous TOMS-Brewer results (Antón et al., 2007). In the previous works, as in Antón et al. (2010), the aerosol effect was studied in terms of aerosol extinction optical depth (AOD) measured at visible $440 \mathrm{~nm}$ wavelength. The comparison results showed that under moderate-high aerosol load $(\operatorname{AOD}(440 \mathrm{~nm})>0.25)$ the OMI bias is about $19-15 \%$ for UVER and spectral UV irradiances. Under cloud-free and low aerosol load conditions (AOD $(440 \mathrm{~nm})<0.1)$ the OMI bias was smaller $\sim 11 \%$ for UVER, and similar spectral results. These studies had not attempted correcting OMI UV data for aerosol absorption, because no information about aerosol absorption properties at UV wavelengths was available at our site.

In this paper we first analyse absorption properties of local aerosols at El Arenosillo site, representative area of South-West Europe, summarizing our previous measurements (Toledano et al., 2007a, b, 2009; Cachorro et al., 2006, 2008; Prats, 2009). Discrimination of absorbing and nonabsorbing aerosols is a challenging task, related to the discrimination of aerosol types. Measurements of AAOD or SSA are routinely available only in the visible wavelengths (440nm and longer wavelengths (Dubovik et al., 2002). The uncertainty of these parameters from AERONET inversions is not yet well-known. Furthermore, the spectral dependence of SSA depends on aerosol type, thus, AERONET SSA values at visible wavelengths can not be simply extrapolated into UV wavelengths (Krotkov et al., 2005, 2009; Arola et al., 2009).

El Arenosillo is an appropriate location for aerosol studies because of a high frequency of cloud-free days, and a great variety of aerosol types with a high occurrence of desert dust outbreaks from Africa during all seasons (Toledano et al., 2007a, b, 2009). In addition, this location enjoys availability of long term measurements of different aerosol types. The period of study is determined by availability of OMI data from October 2004 to December 2008.

The paper is organized as follows. Site characteristics, ground and satellite-based measurements are briefly described in Sect. 2. Section 3 introduces the methodology used for comparison between OMI and Brewer measurements. The comparison results are presented in Sect. 4 with focus on different approaches for OMI aerosol correction. Finally, Sect. 5 summarizes the main conclusions. 


\section{Site, instruments and data}

Short comments about site, instruments and the type of data are given in this paper. For a more detailed description read the earlier mentioned companion paper (Antón et al., 2010).

The site of study is located at "El Arenosillo" Atmospheric Sounding Station (ESAt-El Arenosillo) in Hueva, SouthWest of Spain $\left(37.1^{\circ} \mathrm{N}, 6.7^{\circ} \mathrm{W}, 20 \mathrm{~m}\right.$ a.s.1.). This station belongs to the Earth Observation, Remote Sensing and Atmosphere Department, National Institute of Aerospace Technology of Spain (INTA). This centre participates in the Global Ozone Observing System (GO3OS) of the Global Atmosphere Watch (GAW) program of World Meteorological Organization (WMO) as station \#213. Data gathering, retrieval and reporting procedures at these stations are standardized by the WMO quality assurance procedures.

Aerosol data are provided by the CIMEL-AERONET sunphotometer available since year 2000 (Toledano et al., 2007a, b, 2009). AOD and the derived Ångström coefficient (also denoted by $\alpha$ ) are obtained from direct sun measurements using the current version 2 of AERONET algorithm or by the GOA algorithm (Cachorro et al., 1987, 2001; Ortiz de Galisteo et al., 2009). The AAOD and SSA parameters are derived from the more sophisticated inversion algorithm used by AERONET.

The UV irradiance weighted with the erythemal action spectrum adopted by the Commission Internationale de l'Eclairage (CIE) (McKinlay and Diffey, 1987) (denoted as UVER) and absolute spectral UV irradiances (Watts $/ \mathrm{nm} / \mathrm{m}^{2}$ ) (at $305 \mathrm{~nm}, 310 \mathrm{~nm}$ and $324 \mathrm{~nm}$ ) were used for the comparison between OMI UV products and Brewer measurements.

The OMI instrument is a nadir viewing spectrometer that measures solar reflected and backscattered light in the wavelength range from $270 \mathrm{~nm}$ to $500 \mathrm{~nm}$ with a spectral resolution of $0.45 \mathrm{~nm}$ in the ultraviolet and $0.63 \mathrm{~nm}$ in the visible interval. The instrument has a $2600 \mathrm{~km}$ wide viewing swath and it is capable of daily, global contiguous mapping. The OMI surface UV algorithm (OMUVB) is based on the TOMS UV algorithm developed at NASA Goddard Space Flight Center (Krotkov et al., 2002, 2005; Tanskanen et al., 2007; Torres et al., 2007). In this study OMI UV products correspond to the new version of the OMI level 1 (radiance and irradiance) and level 2 (atmospheric data products) data set named collection 3. This new version takes advantage of a coherent calibration and revised dark current correction. For more information, please, visit the NASA DISC at http://disc.gsfc.nasa.gov/Aura/OMI/ for EOS Aura OMI level 2 orbit data, and the Aura Validation data Center at http://avdc.gsfc.nasa.gov for EOS-Aura OMI station overpass data. Please consult the OMI README files for the latest OMI data product information.

For the latitude of El Arenosillo station, OMI instrument provides more than one overpass per day. In this work, the daily OMI data are derived from the satellite overpass closest to the ground-based location. Thus, the distance between the centre of the satellite pixel and the station vary from $0.1 \mathrm{~km}$ to $48 \mathrm{~km}$, with an average value ( \pm 1 standard deviation) of $(11.5 \pm 8.1) \mathrm{km}$. In addition, Brewer data recorded closest to the selected OMI overpass time (between 12:30 and 14:30 local solar time for El Arenosillo station) were used. The days with differences between the time of Brewer measurements and the OMI overpass time higher than 15 minutes ( $\sim 5 \%$ of all data) are removed in the comparison. Thus, the average of the daily time differences is $(6 \pm 4) \mathrm{min}$.

In a previous paper by Antón et al. (2010), OMI-Brewer irradiance under all-sky conditions with 1206 available data, representing $80 \%$ of total days during the period of study, were compared. In that work, the OMI Lambertian Equivalent Reflectivity (LER) at $360 \mathrm{~nm}$ was used to describe cloud-free conditions. A certain day was classified as cloudfree if LER was lower than 10\% (Kalliskota et al., 2000). Thus, 703 (49\% of the total days) days were selected as cloud-free. In this study, CIMEL AERONET cloud screening data have been also used to define cloud-free conditions, due to the need of simultaneous AOD and OMI-Brewer irradiance data. Thus, the number of selected data is slightly lower, 633 , and finally reduced to 583 (45\% of the total days) in order to use the available SSA values, as we explain below. This high number of values (as was shown in Arola et al., 2009) reflects the good weather conditions of El Arenosillo for solar radiation and aerosol studies, currently providing of one of the best ten AERONET long-continuous data-set, suitable to analyse the OMI bias due to aerosols.

\section{Methodology}

The comparison analysis for irradiance is carried out by regression analysis and also by the mean bias error (MBE) and the mean absolute bias error (MABE). These parameters are defined by:

$$
\begin{aligned}
& \text { MBE }=100 \cdot \frac{1}{N} \sum_{i=1}^{N} \frac{\mathrm{OMI}-\text { Brewer }}{\text { OMI }} \\
& \text { MABE }=100 \cdot \frac{1}{N} \sum_{i=1}^{N} \frac{\mid \mathrm{OMI}-\text { Brewer } \mid}{\text { OMI }}
\end{aligned}
$$

The uncertainty of MBE and MABE is characterized by the standard error (SE). These two statistical parameters were used according to the methodology used in previous works (Antón et al., 2007, 2010).

For the OMI UV data correction, the formula provided by Krotkov et al. (2005) based on the aerosol absorbing correction factor (CAA) was used:

$$
\mathrm{UV}_{\text {corr }}(\lambda)=\mathrm{CAA}(\lambda) \cdot \mathrm{UV}_{\text {operational }}(\lambda),
$$


where $\lambda$ is the corresponding OMI working wavelength in $\mathrm{nm}$. CAA can be estimated by the aerosol absorption optical thickness (AAOD) as follows:

$\operatorname{CAA}(\lambda)=\frac{1}{[1+b \cdot \operatorname{AAOD}(\lambda)]}$

The denominator describes the linear dependence of the overestimation ratio of satellite-based UV on AAOD being $b$ the constant slope. This parameter weakly depends on solar zenith angle (SZA) and aerosol type (Arola et al., 2005; Krotkov et al., 2005). A value of $b=3$ has been used as the most current value. However, according to its definition and following the approach of Kazadzis et al. (2009), the parameter $b$ must be determined from the available data. Although CAA is applied to all OMI UV products, the analysis is restricted to $\lambda=340 \mathrm{~nm}$ which is the single wavelength available for AAOD.

Therefore, AOD and AAOD (or the equivalent SSA) at UV wavelengths are necessary for OMI correction data. AAOD (or SSA) needs more sophisticated inversion algorithms for its determination, presenting a high uncertainty when available. These parameters are retrieved at visible-NIR spectral range by the AERONET inversion algorithm. This algorithm is based on almucantar radiance data, restricting SZA to high values and with others limitations, such as $\operatorname{AOD}(440 \mathrm{~nm})$ greater than 0.4. All these restrictions considerably reduce the number of available site-data. In the UV range, AOD values are more scarce than those at visible or near infrared in AERONET stations. In addition, there is no current retrieval methodology available with AERONET data for AAOD or SSA in the UV range. To overcome this issue, Krotkov et al. (2005) used UV-MFRSR radiometer aerosol data, and in the works of Kazadzis et al. (2009) and Ialongo et al. (2010) all the aerosol information was derived from Brewer measurements. However, these methodologies present some limitations for aerosol retrieval radiative properties due to the low intrinsic sensitivity of SSA to UV irradiance values.

SSA is a function of the wavelength and this dependence can be used to define the aerosol type. Most current discrimination of aerosol types is based on AOD-alpha plots information (Eck et al., 1999; Toledano et al., 2007a) which may give additional information to select partially absorbing aerosols, but not to retrieve reliable absorbing properties. Therefore, here different approaches will be followed, from AERONET aerosol information based only on AOD-alpha to a more detailed approaches based on SSA or AAOD.

Moreover, Aerosol index AI (Hsu et al., 1999; Torres et al., 1999) provided by the OMI sensor also gives information about absorbing aerosols. In this study, this approach has been explored in correspondence with AOD-alpha or SSA values in order to get more detailed aerosol information.

\section{Results and discussion: aerosol effect on OMI bias}

The results of our previous paper of Antón et al. (2010) must be borne in mind for this analysis. The overestimation of OMI irradiance values about $13 \%$ for cloud-free conditions and the initial evaluation of aerosol influence were very informative. Nevertheless, that paper did not analyse the influence of absorbing and non-absorbing aerosols on the observed OMI bias and hence no correction could be applied.

It is needed to achieve a more detailed analysis of absorbing aerosols in order to correct its effect on OMI bias. This topic will be discussed in the next sections. However, the first issue is how to identify absorbing aerosols. As already mentioned different approaches have been considered depending on the available aerosol information.

\subsection{Absorbing aerosol determination based on AOD-alpha and AI information}

A first approach for determining absorbing aerosols based on AOD-alpha information was evaluated and its relationship with OMI bias was investigated. The most common and widely available information about aerosol properties are AOD and alpha parameters. Thus, climatological tables for both parameters are provided by AERONET. However, this is not the case for SSA.

Values of AOD at UV wavelengths are needed to perform this analysis. The standard sun-photometer installed at El Arenosillo has no measurements at UV wavelengths since it is a polarized instrument. In order to overcome this drawback, AOD at $340 \mathrm{~nm}$ was measured by another Cimel photometer which was installed at our station between June 2006 and August 2007 within the period of study. Thus, AOD values at $440 \mathrm{~nm}$ and the alpha parameters have been used to extrapolate the AOD to UV wavelengths. This approach has been validated using the measurements of AOD values at $340 \mathrm{~nm}$. In this sense, Fig. 1a shows a good agreement between the measured and calculated values at $340 \mathrm{~nm}$.

It would be desirable to have AOD values at shorter UV wavelength, lower than $340 \mathrm{~nm}$, but only Cimel data at this wavelength are available at this moment. AOD Brewer data were not used in this work since there is currently a high disagreement between our retrieved Brewer data and Cimel data at UV wavelengths. Although many works give a good assessment about AOD Brewer retrieval (e.g., Gröbner et al., 2001; Marenco et al., 2002; Gröbner and Meleti, 2004; Kazadzis et al., 2005, 2007; Cachorro et al., 2009) some problems remain that must be solved to have reliable Brewer AOD data in an operational way, without additional measurements as in the works by Kazadzis et al. $(2005,2007)$. Further improvements are necessary in calibration constants to obtain operational AOD Brewer data.

It is interesting to analyse the relationship between $\operatorname{AOD}(340 \mathrm{~nm})$ and $\operatorname{AOD}(440 \mathrm{~nm})$ (Fig. 1b) since part of the information given at UV range is derived from visible 

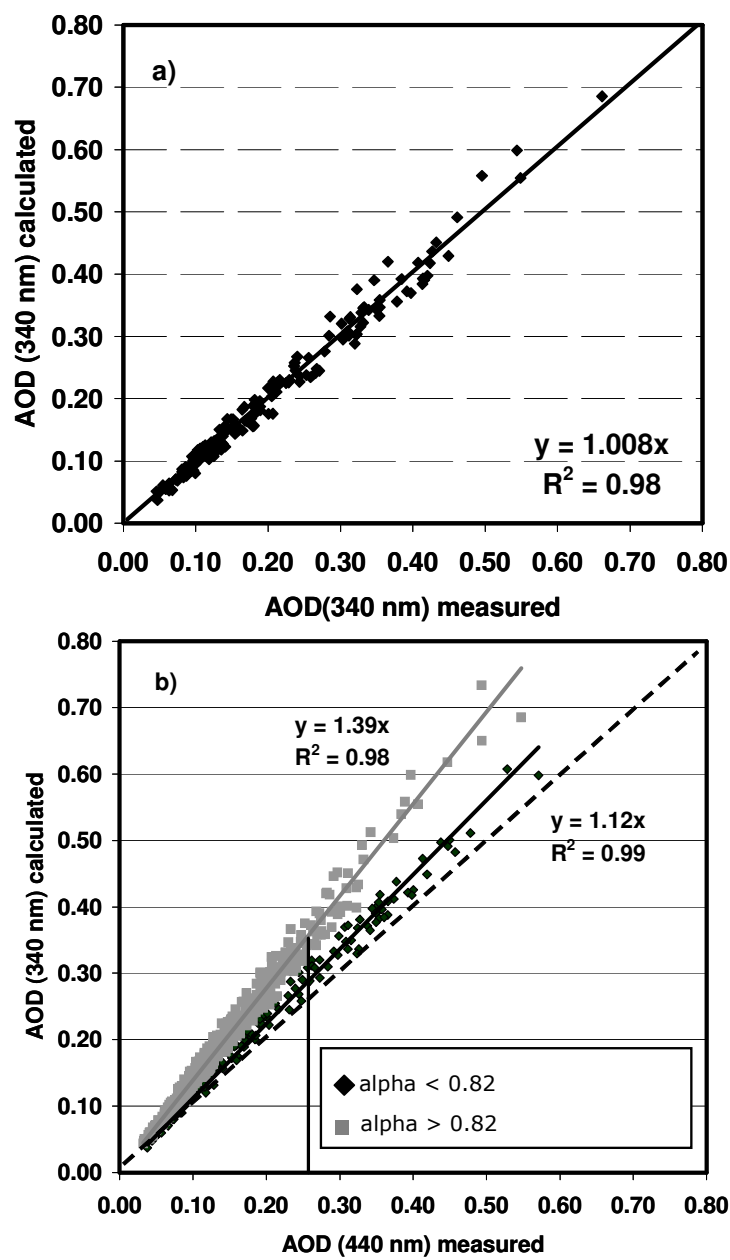

Fig. 1. (a) Calculated AOD at $340 \mathrm{~nm}$ (based on extrapolated data at $440 \mathrm{~nm}$ using the alpha climatological AERONET values) as function of measured AOD at $340 \mathrm{~nm}$ during a year of measurements and its fit; (b) calculated AOD values at $340 \mathrm{~nm}$ as function of the measured AOD at $440 \mathrm{~nm}$ during the analysed period (2004-2008) for alpha less and greater than 0.82 . Also both fits are shown.

spectral range and in this case, by the alpha coefficient or Ångström exponent $\alpha$ (hereafter we use indistinctly alpha or $\alpha$ ). The plot shows two branches: one corresponding to the black points and the other to the grey points. This behaviour could disagree with the expected more linear correlation between both wavelengths (or between others pair of wavelengths: i.e., 440-670, etc.). Nevertheless, this behaviour appears when there are two well defined groups of size particles.

These findings are based on the characterization of AODalpha aerosol climatology in El Arenosillo given by Toledano et al. (2007a). The histogram of frequencies of the alpha parameter given in Fig. 2a (see also Fig. 7 in Toledano et al. (2007a) for the period 2000-2005) shows two separated modes at $\alpha=0.82$, defining coarse and fine-moderate size
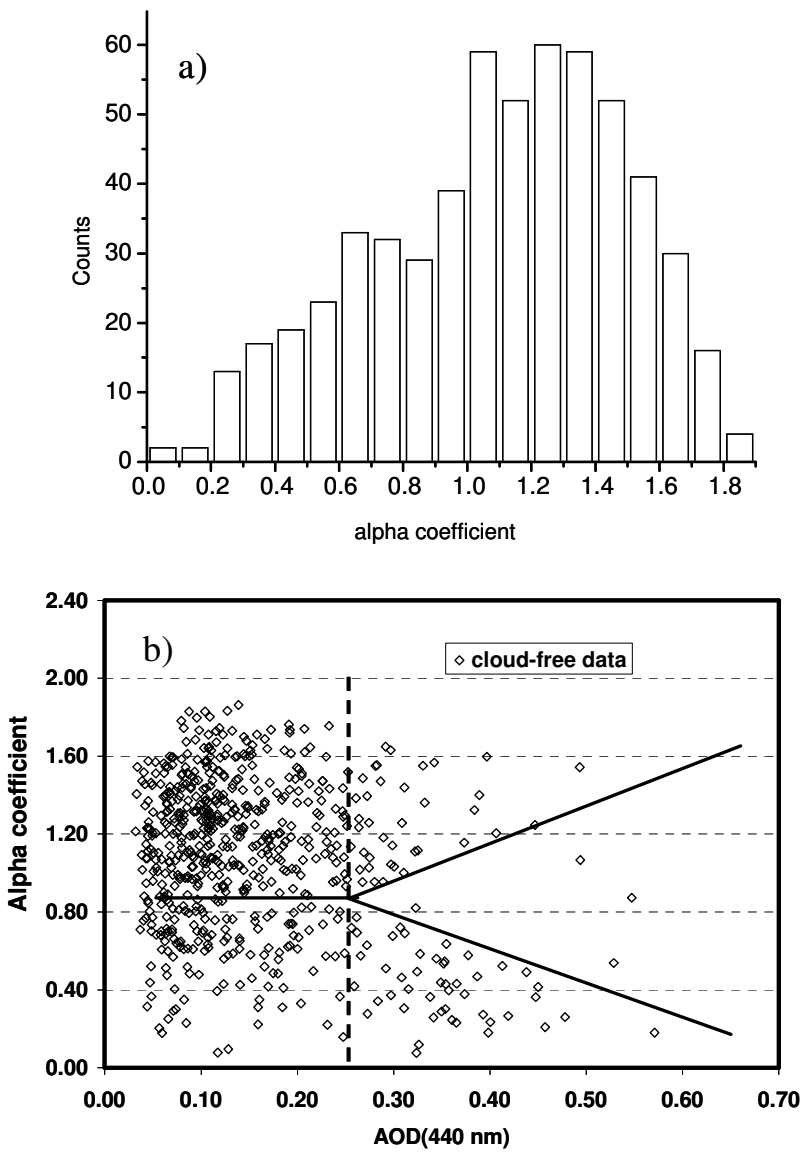

Fig. 2. (a) Frequency histogram of alpha values and (b) plot of alpha versus AOD at $440 \mathrm{~nm}$ during the analysed OMI period (20042008) under cloud-free conditions.

particles. The peak of the coarse mode, about $\alpha=0.5$, is mainly due to desert dust aerosol type and the other mode (about $\alpha=1.2$ ) is mainly related to the prevailing coastal marine aerosols. Fine particles have a low weight in the histogram for our station but, in the latter mode, continental aerosol type and fine particles associated with polluted or other type of events have been included.

Hence, the cloud-free data set have been divided into two groups, one of alpha values smaller than 0.82 and another one with values equal or greater than 0.82 (representing the $28.3 \%$ and $71.7 \%$ of all cloud-free cases, respectively) according to the information given by Figs. $1 \mathrm{~b}$ and 2a. In addition, both modes or branches can be clearly distinguished in Fig. 1b when the value of $\operatorname{AOD}(440 \mathrm{~nm})$ reaches 0.25 . For $\operatorname{AOD}(440 \mathrm{~nm})$ values lower than 0.25 both branches are joined, being difficult to separate both groups. Therefore, $\operatorname{AOD}(440 \mathrm{~nm})=0.25$ is considered as the limiting point between both branches. The additional information given by the alpha parameter allows us to perform this separation for lower $\operatorname{AOD}(440 \mathrm{~nm})$ values. Figure $2 b$ shows the relationship between the alpha coefficient and AOD at 
$440 \mathrm{~nm}$. Two data sets of $\operatorname{AOD}(440 \mathrm{~nm}) \geq 0.25$ and one data set $\operatorname{AOD}(440 \mathrm{~nm})<0.25$. can be very clearly seen. These two groups of high AOD differentiate between moderate-fine (alpha greater than 0.82) related to polluted aerosol episodes and large particles (alpha smaller than 0.82) associated with desert dust particles. Hence, it is expected that these two groups may represent absorbing aerosols.

We recall that desert dust (DD) aerosols attenuate the UV radiation more strongly than other aerosol types with the same AOD due to their low single scattering albedo at UV wavelengths (Krotkov et al., 1998; Meloni et al., 2003). In the case of our area of study and taking into account their characteristics (Toledano et al., 2007a, b) polluted aerosols are represented by those arriving from industrialurban areas mixed with marine or continental aerosols, but not pure coastal-marine aerosols $(\operatorname{AOD}(440 \mathrm{~nm})$ lower than $0.25)$. However, values of high alpha and $\operatorname{AOD}(440 \mathrm{~nm})$ may also correspond to biomass-burning (BB) aerosols. This type of aerosols corresponds to isolated episodes well identified in our station (Cachorro et al., 2008). These aerosols are mainly related to cases of local forest fires and those arriving from Portugal during the period of study. BB aerosols correspond to 5-6 points and, hence, represent a low percentage of the total number of cases (about $0.5-1 \%$ ).

Figure $3 \mathrm{a}$ shows the relationship between the relative differences OMI-Brewer and the valid associated values of AOD at $340 \mathrm{~nm}$ for cloud-free conditions (white rhomboid points). A very low correlation is found with $R^{2}=0.16(R=$ $0.4)$. This correlation is notably improved when data with alpha below 0.82 are selected (grey points), giving $R^{2}=0.42$ (or $R=0.65$ ). The set of values with $\operatorname{AOD}(440 \mathrm{~nm})>0.25$ and $\alpha \geq 0.82$ is shown as red points. The relationship between OMI-Brewer differences and AOD at $340 \mathrm{~nm}$ presents a great variability, depending on the site or aerosol type (e.g., Kazantzidis et al., 2006; Ialongo et al., 2008; Buchard et al., 2008). Antón et al. (2007) found a better correlation for binned data, showing clearly that the OMI bias increases as the AOD increase. Note that this result is relevant it is the same that working with the case of SSA constant as we will discuss later in this paper.

In order to gain more information about our aim to select absorbing aerosols, Fig. $3 \mathrm{~b}$ shows the differences OMIBrewer as function of AI. Similar to above, regressions were obtained showing very poor correlation values. However, according to AI values most points of the selected set of high $\operatorname{AOD}(440 \mathrm{~nm})$ appear as non-absorbing (red points) with the exception of few of them with AI values greater than 0.5 , corresponding to $\mathrm{BB}$ aerosols (located close but at the right of the vertical line $\mathrm{AI}=0.5$ ). We have taken $\mathrm{AI}=0.5$ as the limiting value between absorbing and non-absorbing aerosol according to Krokov et al. (2005). The other set with $\operatorname{AOD}(440 \mathrm{~nm})>0.25$ and $\alpha<0.82$ correspond to desert dust (DD) which is located at the top-right, appearing as absorbing data.
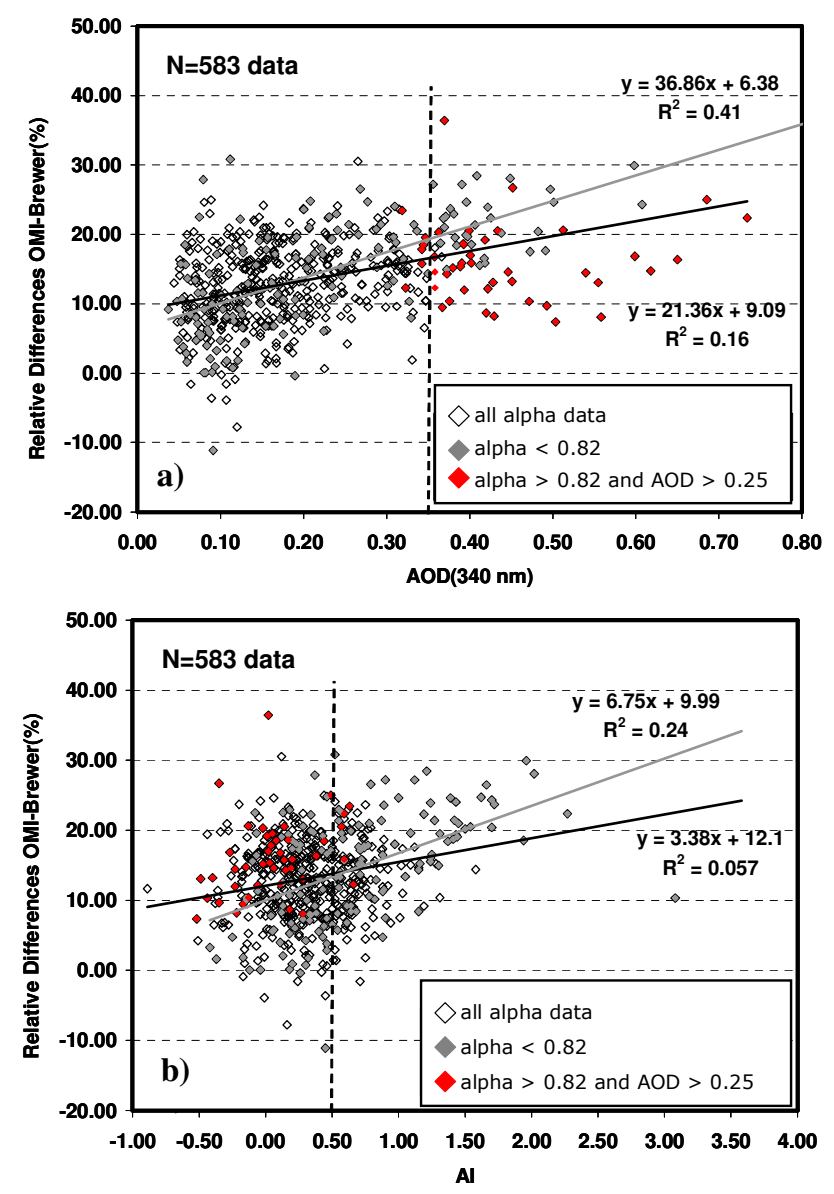

Fig. 3. (a) Dependence of the relative difference between OMI and Brewer UVER with respect to the aerosol optical depth (AOD) at $340 \mathrm{~nm}$ for cloud-free conditions. The two fits are shown (b) OMI bias as function of AI index where different subsets of aerosols specified by alpha and AOD values are represented (see text). "all alpha data" set includes white, grey and red points.

We have plotted AOD $(440 \mathrm{~nm})$ versus AI in Fig. 4 in order to improve the classification of absorbing aerosols. Most red points are in the first quadrant except the points corresponding to the mentioned biomass burning (BB). This result was not expected as indicated above (Fig. 3b) since red points were expected at the top-right quadrant. Grey points (alpha smaller than 0.82) are located in the other three quadrants. The right-top quadrant defines the desert dust (DD) and biomass-burning BB cases as expected.

$\mathrm{AI}$ is an efficient way to detect absorbing aerosols, but it is more difficult to retrieve since it is also sensitive to AOD and SSA quantitative information. Bear in mind that AI is very sensitive to the aerosol altitude and increasing with altitude, if other relevant factors, as AOD and SSA are the same, hence not very sensitive to the presence of aerosols in the boundary layer or low layers in the troposphere. Therefore, the red points may provide more 


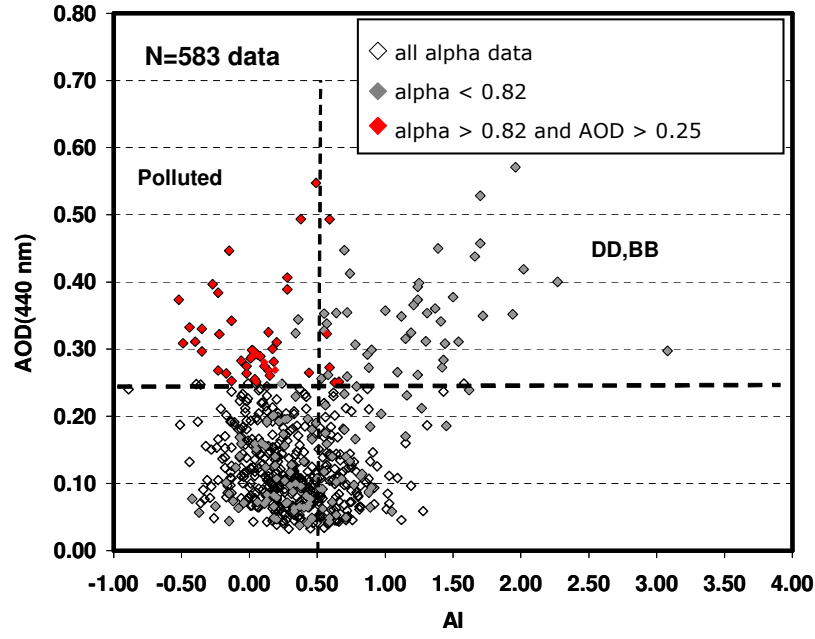

Fig. 4. AOD at $440 \mathrm{~nm}$ as function of $\mathrm{AI}$ index where different subsets of aerosols are indicated. "all alpha data" set includes white, grey and red points.

information about the altitude than about the strength of absorption. These red points may be associated with polluted boundary layer aerosols and also related to sulphates composition (Gonzalez-Castanedo, 2007) or more scattering aerosols. Because of this apparent inconsistency in the classification of absorbing and non-absorbing aerosols based on AOD-alpha and AI information, the available values of SSA will be used in the next section.

\subsection{Absorbing aerosol based on SSA values and its relation with $\mathrm{AOD}$, alpha and $\mathrm{AI}$}

Two groups of high AOD(440 nm) with potential absorbing properties have been selected, with alpha smaller and greater than 0.82 . It is worth noting that they only correspond to a small subset of the total free-cloud data (15\%). Figures 3-4 show the behaviour of these two subsets and also the whole data set in order to distinguish the different absorbing features of these data. Due to the insufficient information with $\mathrm{AI}$ and AOD-alpha parameters, the available SSA values at our station given by AERONET must be considered, as the most relevant parameter to define the absorbing properties of aerosols.

AERONET provides SSA (or AAOD) values at two level of quality (level 1.5 is cloud screening and level 2 requires post-calibrated data together with manual inspection) and at the four aerosol wavelengths $(440,670,870,1020 \mathrm{~nm})$ according to AERONET inversion algorithm (Dubovik and King, 2000; Dubovik et al., 2002). However the climatological studies of these SSA data are not usually feasible at most AERONET sites. Level 2 for SSA requires a set of restrictions for inversion: post-calibrated data, SZA greater than $50^{\circ} ; 21$ azimuth angles, high AOD values, etc., (see for detail, http://aeronet.gsfc.nasa.gov/new_web/
Documents/AERONETcriteria_final1.pdf, and Prats et al., 2008), which reduce considerably the data and hence it is difficult to have a representative climatology. The restriction of $\operatorname{AOD}(440 \mathrm{~nm}) \geq 0.4$ eliminates most of the aerosol data, as in the case of our station.

All these conditions make impossible to obtain a climatology based on AERONET level 2 data nor a reliable seasonal characterization at El Arenosillo in spite of using more than nine continuous years of data and taking into account its excellent weather conditions (Prats et al., 2008). Furthermore, the low number of data is not sufficient to analyse OMI irradiance data and they are only representative of desert dust aerosols (Toledano et al., 2007b). Therefore it was necessary to take SSA level 1.5. Mean daily values (not overpass data) were used as the most reliable values for this analysis because of the restrictions of the inversion AERONET algorithm for SZA as mentioned above. The error of SSA reported by AERONET depends on the values of $\mathrm{AOD}(440 \mathrm{~nm})$ and also on aerosol types (DD, BB, etc.), with higher uncertainty for lower wavelengths (Dubovik et al., 2002), varying from 0.03 to 0.07 .

In spite of this assigned error, it must be emphasized that the quality of the obtained SSA data-set "(level 1.5)" is not guaranteed (quality not assured according to AERONET protocols). In addition, the analysis of the SSA quality with other methodology is not generally feasible. This is the case for our study and unfortunately for other reported cases (Pére et al., 2009). To solve this problem, the work of Arola et al. (2009) proposed to use model data in combination to AERONET data in order to get a climatology expressing the SSA values as monthly-means. Also monthly SSA values were used in the work of Kazadzis et al. (2009) but using other methodology based on Brewer global-direct measurements and a radiative transfer model. For the moment, only AERONET data are available at El Arenosillo station

Figure 5a shows SSA versus AOD, both taken at $440 \mathrm{~nm}$ wavelengths. A first look of this plot indicates that SSA values range from 0.7 to 1 with a $66 \%$ of points between 0.9 and 1. In addition, there is a significant number of points below $0.85(14 \%)$, presenting most of then $\operatorname{AOD}(440 \mathrm{~nm})$ smaller than 0.25 . The cases with $\operatorname{SSA}(440 \mathrm{~nm})$ smaller than 0.9 and $\operatorname{AOD}(440 \mathrm{~nm})$ smaller than 0.25 represent $29 \%$ of all. Our selected two groups of data with $\operatorname{AOD}(440 \mathrm{~nm}) \geq 0.25$ appear as the top-right side, with most of them with SSA values between 0.9-1 which indicates that they are not absorbent, as it was expected. The cloud-free data set has a mean value of $\operatorname{SSA}(440 \mathrm{~nm})=0.9$ and its most frequent value is 0.95 (histogram of frequencies not shown). Also it can be seen that the alpha values are more or less homogeneous distributed around all the SSA range, not being associated with the absorbing characteristics.

In Fig. 5b SSA $(440 \mathrm{~nm})$ values are plotted versus AI for the whole data set and the set of alpha smaller than 0.82 together with both sub-groups of $\operatorname{AOD}(440 \mathrm{~nm}) \geq 0.25$ (red and green points). It can be seen that there is no correlation 

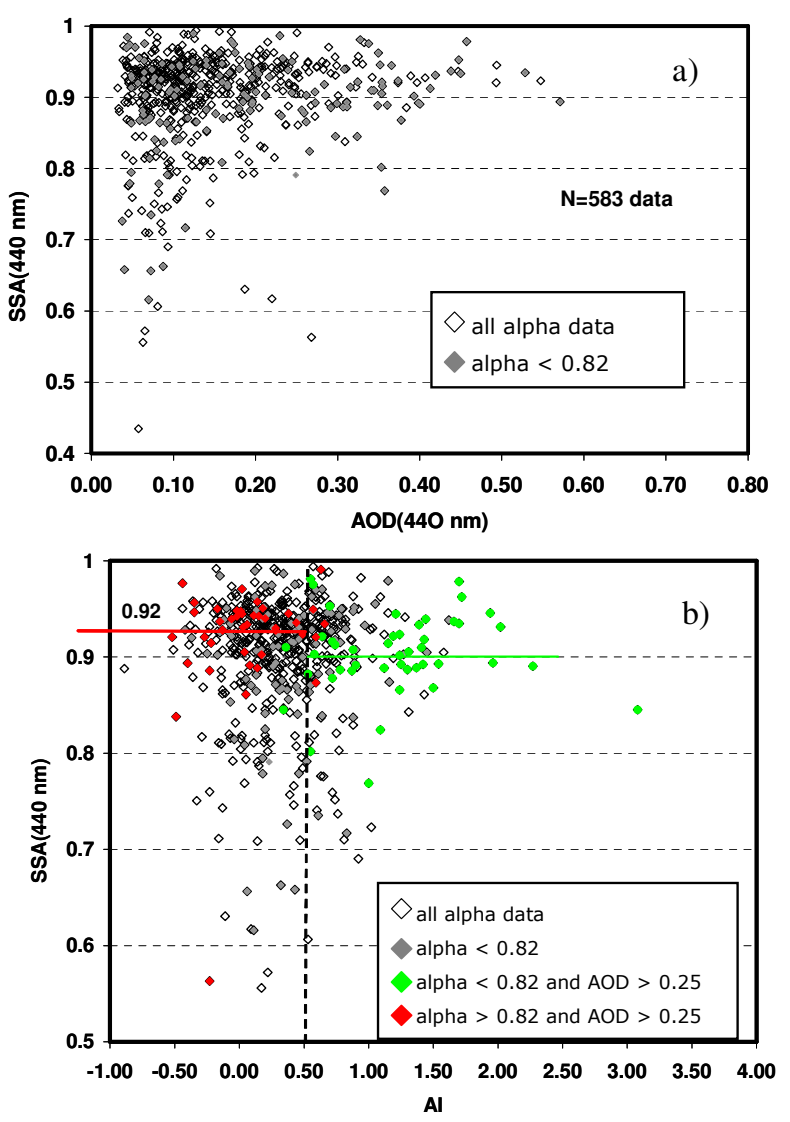

Fig. 5. (a) Mean day values of SSA at $440 \mathrm{~nm}$ "(level 1.5)" as function of AOD at $440 \mathrm{~nm}$ for the El Arenosillo station for the 2004-2008 period and (b) as function of AI, where different subsets of aerosols specified by alpha and $\operatorname{AOD}(440 \mathrm{~nm})$ values are represented (see text). "all alpha data" set includes white and other coloured points.

as it could be expected. Appearing at the left of $\mathrm{AI}=0.5$ most of the points correspond to moderate-low absorption around SSA $=0.92$ and a non-neglected number of points show very low SSA values (high absorption) which correspond to $\operatorname{AOD}(440 \mathrm{~nm})$ lower than 0.25 . As before, red points (polluted) appear as non-absorbing according to AI but with a mean SSA value of 0.92 , thus as moderately absorbing. Green points or desert dust (DD) have a mean value of SSA $=0.9$ (lower than red points), giving also lowmoderate or non pronounced absorbing characteristics. It must be emphasized that these same points appeared as absorbing aerosols according to AI (right side). In conclusion, AI and SSA values do not show contradictory information to define absorbing aerosol groups. It is difficult to choose what experimental values (AI or SSA) are most adequate to describe absorbing aerosol properties, although the SSA parameter appears as the most reliable according to Mie theory.

For the OMI bias correction it is necessary to obtain the SSA at UV wavelengths where no retrieval methodology is currently available with AERONET data. In order to solve this issue, we extrapolate from $440 \mathrm{~nm}$ to $340 \mathrm{~nm}$ assigning the same slope that SSA has between 440 and $670 \mathrm{~nm}$ as a good approach. Figure 6 shows the correlation between the SSA at $440 \mathrm{~nm}$ and at $340 \mathrm{~nm}$. The agreement is high with a correlation coefficient $\left(R^{2}\right)$ of 0.97 , being the values at $340 \mathrm{~nm}$ slightly higher than at $440 \mathrm{~nm}$. To illustrate the spectral behaviour of SSA, Fig. 7 depicts the mean value of SSA "(level 1.5)" for the four aerosol wavelengths used in AERONET during the whole OMI analysed data set in El Arenosillo. Also it is depicted the SSA values of the whole data-set without desert dust (DD) group and the SSA of the DD group. As can be seen, the SSA decreases for larger wavelength and the contrary happens for DD aerosols. Slightly lower values have been obtained for the period 2000-2009, as shown below in Fig. 8a.

The SSA values obtained in El Arenosillo are, in general, quite lower (more absorbing) than those found in other areas. Our values are equivalent or lower than those found in big urban cities as Paris or Mexico D.F., or more polluted areas as the site of the GSFC (Goddard Space Flight Center) at Greenbelt near Washington-DC, as it is depicted in Fig. 8b. The three AERONET sites have a long-record of data as indicated in Fig. 8b for level 1.5 and 2 where the observed difference are sufficient illustrative to put in discussion the true validity of " 1.5 level" data.

To confirm these non-expected high absorbing values of SSA in El Arenosillo, we have also analysed the SSA values for our AERONET station of Palencia in the North of Spain $\left(41.98^{\circ} \mathrm{N}, 4.51^{\circ} \mathrm{W}, 750 \mathrm{~m}\right.$ a.s.1.). Although the site is located near a little city of 82000 inhabitants without industry, very low values of SSA are not expected. In Fig. 8a the earlier SSA values in El Arenosillo are depicted together with those in Palencia for level 1.5 and 2. It can be seen that SSA values in level 1.5 are lower in Palencia than in El Arenosillo. It must be noted that level 2 is represented by the features of desert dust aerosols where SSA increases with the wavelength, because in both sites only DD intrusions reach values of $\operatorname{AOD}(440 \mathrm{~nm})$ as high as 0.4 to reach level 2. Therefore, this is a non expected result because El Arenosillo is located in a rural area and although it may have some influence of the industrial belt of the city of Huelva, this can not reach this lower SSA values. Observe that GSFC at level 2 has a value of SSA at $440 \mathrm{~nm}$ higher than 0.95 and at UV about 0.98 , thus appearing as a reliable value. On the other hand, the error of SSA reported by AERONET depends on the values of $\mathrm{AOD}(440 \mathrm{~nm})$ and also on aerosol types (DD, BB, etc.), with higher uncertainty for lower wavelengths (Dubovik et al., 2002), varying from 0.03 to 0.07 .

The above results show the current state of the research about the values and uncertainties of the SSA parameter. In spite of these shortcomings, the SSA values "(level 1.5)" will be used to analyse their relationship with the OMI irradiance correction. 


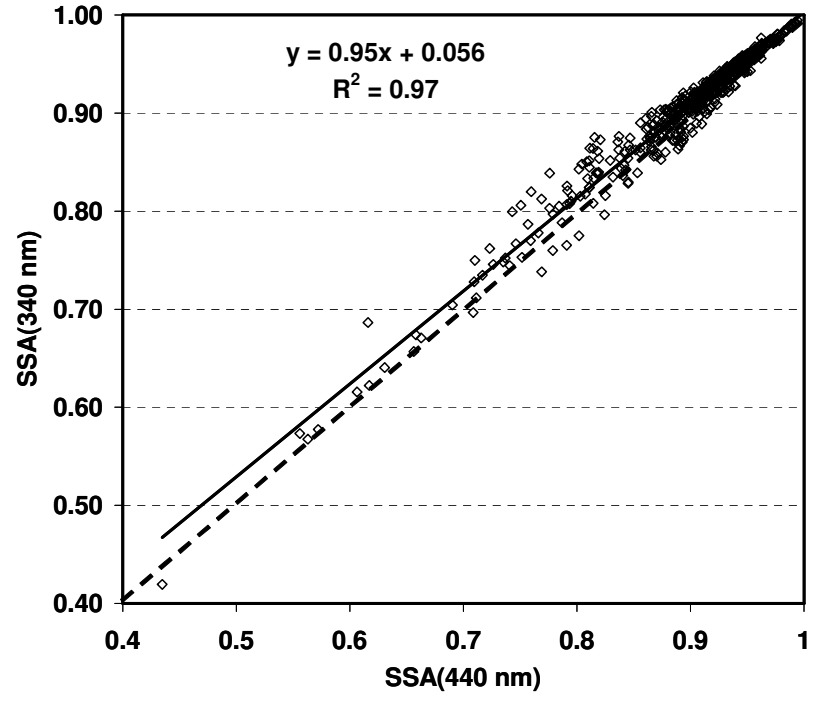

Fig. 6. Correlation and fit of SSA at $340 \mathrm{~nm}$ and $440 \mathrm{~nm}$.

\subsection{Application of corrections for OMI bias - approaches of SSA constant and SSA variable}

The SSA of DD aerosols increase as the wavelengths increase (Dubovik et al., 2002) in contrast with the behaviour of the SSA for the whole data set (with and without DD aerosols) which decreases. Because of this opposite spectral behaviour both sets have the same value of 0.916 for $340 \mathrm{~nm}$, when the straight line that joins the SSA values at the wavelengths of 440 and $670 \mathrm{~nm}$ is extrapolated. We must also note that the spectral behaviour of the red points is very similar to the spectral behaviour of the whole data set. Therefore, as first approach a fixed SSA value of 0.916 will be considered to generate the $\mathrm{AAOD}=(1+\mathrm{AOD} \cdot \mathrm{SSA})$ at $340 \mathrm{~nm}$ for the whole data set. In this case, the AAOD variation is exclusively due to AOD changes. As second approach, AAOD values are derived from average daily values of SSA at $340 \mathrm{~nm}$. In this second case, the slope of the line between $440 \mathrm{~nm}$ and $670 \mathrm{~nm}$ was evaluated to get the value of SSA at $340 \mathrm{~nm}$ for each individual spectral data of SSA. Thus, while AAOD values range from 0 to almost 0.07 for the first approach, they reach more than the double value $(\sim 0.17)$ for the second approach.

The two plots of Fig. 9 show the relationship between OMI/Brewer ratio for UVER and AAOD at $340 \mathrm{~nm}$ obtained by means of the first approach (top) and the second one (bottom). The fitting has been added to each plot in order to determine the parameter $b$ of the correction formula for the two approaches. The value $b=3.42$ was obtained for the first approach which is near the proposed value of Krotkov et al. (2005) and $b=1.155$ for the second approach taking $\operatorname{SSA}(340 \mathrm{~nm})$ variable. Both fits show very poor correlation with coefficient of determination $R^{2}$ equal to 0.17 and 0.04 , respectively. The constants for the spectral irradiances

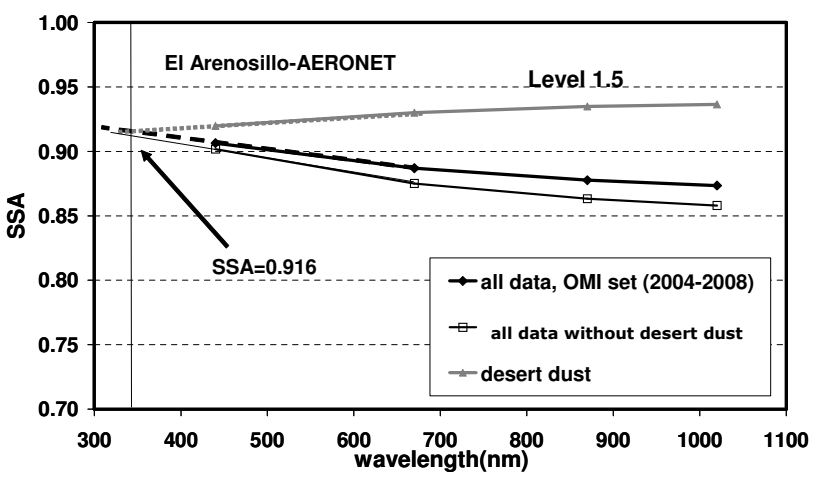

Fig. 7. The mean values of SSA as function of wavelengths (level 1.5) for the period 2004-2008. The SSA spectral mean value when desert dust data are removed from the total and the spectral SSA for desert dust aerosol (this behaviour is the same as that given by level 2 SSA).
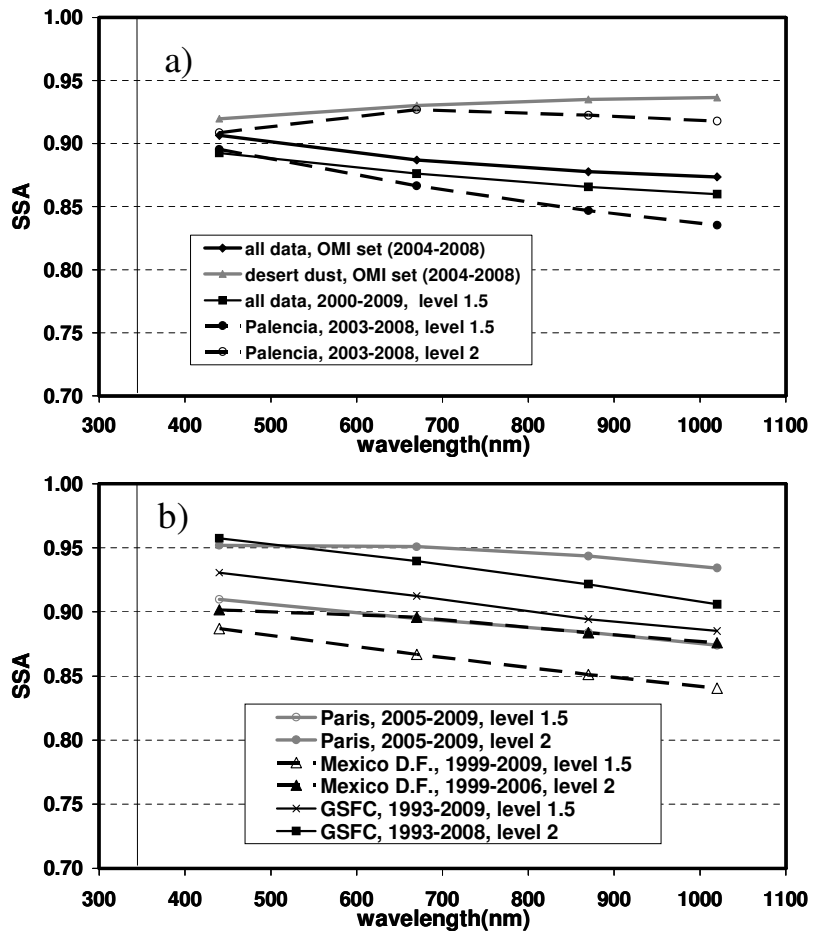

Fig. 8. (a) Mean values of the spectral SSA for level 1.5 of El Arenosillo for the periods 2004-2008 (used with OMI data) and 2000-2009; SSA for desert dust only for the period 2004-2008 and those of Palencia station as indicated. (b) The same for three representative cities (Paris, Mexico D.F. and GSFC at Greenbelt near Washington-DC) and their corresponding periods of data for level 1.5 and 2 .

at 305,310 and $324 \mathrm{~nm}$ were also obtained and given in Table 1 (plot are not shown).

Figure 10 shows the correlation between OMI and Brewer values for UVER before and after the correction using the 

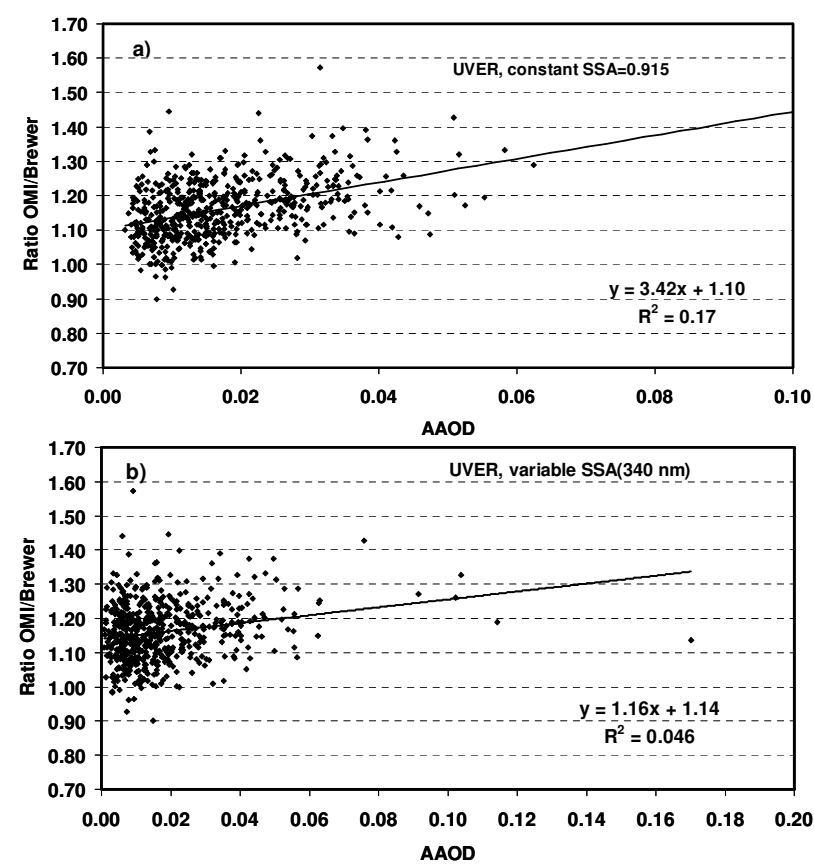

Fig. 9. Ratio of OMI/Brewer UVER data as function of aerosol absorption optical depth AAOD(440 nm) and the corresponding fits for $b$ determination (a) first approach based on $\operatorname{SSA}(340 \mathrm{~nm})$ constant and (b) second approach based on SSA $(340 \mathrm{~nm})$ variable.

first approach (top) and the second one (bottom). Table 2 contains all the information of slopes and intercepts values and statistical parameters for UVER, 305, 310 and $324 \mathrm{~nm}$ wavelengths. The regression analysis without correction shows positive OMI bias characterized by regression slopes of 1.18 (UVER), 1.18 (UV $305 \mathrm{~nm}$ ), and 1.14 (UV $310 \mathrm{~nm}$ ), and 1.10 (UV $324 \mathrm{~nm}$ ), and with coefficients of determination higher than 0.96. The RMSE statistics (residual error of the fit) is $7.1 \%$ for UVER and between $6 \%$ and $8.3 \%$ for spectral wavelengths, being larger for shorter wavelengths in agreement with the work of Kazadzis et al. (2009). The values of the MBE (Mean Bias Error) parameters are 13.38\% (UVER), $14.92 \%$ (UV at $305 \mathrm{~nm}$ ), $11.75 \%$ (UV at $310 \mathrm{~nm}$ ) and $10.30 \%$ (UV at $324 \mathrm{~nm}$ ), indicating the notable agreement between satellite and ground-based irradiance data in our area, as has been reported previously (Antón et al., 2010).

The correction of the OMI irradiance data (Eqs. 3 and 4) reduces significantly the bias with respect to Brewer measurements. Table 2 shows that MBE for UVER decreases to $11.65 \%$ (SSA variable approach) and $8.4 \%$ (SSA constant approach), which represents a relative decrease of $13 \%$ and $37 \%$ with respect to the values without correction. Similar improvement was obtained for the three spectral wavelengths. The smallest bias corresponds to wavelengths at $310 \mathrm{~nm}(6.9 \%)$ and $324 \mathrm{~nm}(6.3 \%)$ for the SSA constant approach, representing a relative reduction of OMI bias of $32 \%$ and $38 \%$, respectively.
Table 1. Results of linear regression analysis between OMI/Brewer ratio of UV products and AAOD at $340 \mathrm{~nm}$ for the two approaches: SSA variable and SSA constant. The parameters are the following: the slope of the regression $(b)$, the $Y$ intercept, and the correlation coefficient $\left(R^{2}\right)$.

\begin{tabular}{llll}
\hline SSA variable & $b$ (Slope) & $Y$ intercept & $R^{2}$ \\
\hline UVER & 1.16 & 1.14 & 0.05 \\
305 & 1.07 & 1.16 & 0.03 \\
310 & 1.09 & 1.12 & 0.04 \\
324 & 1.01 & 1.10 & 0.04 \\
\hline SSA constant & $b$ (Slope) & $Y$ intercept & $R^{2}$ \\
\hline UVER & 3.42 & 1.10 & 0.17 \\
305 & 2.44 & 1.12 & 0.13 \\
310 & 3.28 & 1.08 & 0.15 \\
324 & 2.67 & 1.17 & 0.13 \\
\hline
\end{tabular}

As can be seen a better improvement has been obtained for the SSA constant approach which may be surprising in principle, but not taking into account the above discussion about SSA values. A fixed value of SSA equal to 0.916 at UV range is more reliable for the whole data set that the variable values of SSA "(level 1.5)". As it was discussed above, AAOD values obtained for SSA variable appear as a whole as very absorbing, reaching a value of 0.17 . The correlation between these two sets of AAOD values has been evaluated showing a low correlation, smaller than 0.3 (not shown). Thus, the constant slope $b$ in the SSA variable approach decreases considerably, reducing the posterior effectiveness of the correction (see that $b=1.155$ is near 1 ). When values greater than 0.08 are removed, a value of $b=1.49$ is obtained but the improvement is not significant.

Otherwise, if a value of $b=3$ is applied (Krotkov et al., 2005) the OMI bias of UVER decreases to $9.4 \%$ (324 nm falls to $4.5 \%$ ) but the application of this value is not justified. Additionally, it is worth noting that for the second approach using SSA at $440 \mathrm{~nm}$ instead of at $340 \mathrm{~nm}$ gives the same results. Also, the performance of the correction has been evaluated in the case of using a constant value of SSA equal to 0.95 , which may be a reasonable value for the whole data set assuming less absorption, as in the area of GSFC (where the interpolated value goes to 0.95 at UV range). In this case, the slope $b$ increases up about 5 but the AAOD values decrease in such a way that the correction factor, and hence the correction, are substantially modified. Thus, these other explored possibilities or approaches do not improve the previous one.

Figure 11 depicts OMI bias as function of $\operatorname{AOD}(340 \mathrm{~nm})$ before (same as earlier Fig. 3a) and after the application of the two corrections. Now no dependence is observed with horizontal slopes for the regression lines after the correction. Tanskanen et al. (2007) showed that the OMI-derived daily erythemal doses (uncorrected for absorbing aerosols) have 
Table 2. Results of linear regression analysis between OMI and Brewer UV products without correction and the correction for the two approaches: SSA variable and SSA constant, and the statistical parameters of relative differences. The parameters are the following: the slope of the regression, the standard error (SE) of the slope, the $Y$ intercept, the SE of the $Y$ intercept, the correlation coefficient $\left(R^{2}\right)$, the root mean square errors (RMSE), the number of data $(N)$, the mean bias error (MBE), the standard error (SE) of the MBE, the mean absolute bias error (MABE), and the SE of the MABE.

\begin{tabular}{|c|c|c|c|c|c|c|}
\hline \multicolumn{7}{|c|}{ WITHOUT CORRECTION } \\
\hline & lope & SE (Slope) & $\begin{array}{r}Y \text { intercept } \\
\left(\mathrm{mW} / \mathrm{m}^{2}\right)\end{array}$ & $\begin{array}{r}\text { SE (Y intercept) } \\
\left(\mathrm{mW} / \mathrm{m}^{2}\right)\end{array}$ & \multicolumn{2}{|r|}{ RMSE (\%) } \\
\hline UVER & 1.18 & 0.01 & -1.89 & 1.08 & 0.98 & 7.16 \\
\hline 305 & 1.18 & 0.01 & 0.10 & 0.27 & 0.98 & 8.35 \\
\hline 310 & 1.14 & 0.01 & -0.07 & 0.55 & 0.97 & 7.42 \\
\hline \multirow[t]{2}{*}{324} & 1.10 & 0.01 & 5.37 & 2.85 & 0.96 & 6.56 \\
\hline & $\mathrm{N}$ & $\operatorname{MBE}(\%)$ & SE (MBE) (\%) & MABE (\%) & \multicolumn{2}{|c|}{$\mathrm{SE}(\mathrm{MABE})(\%)$} \\
\hline UVER & 583 & 13.38 & 0.26 & 13.48 & \multicolumn{2}{|r|}{0.25} \\
\hline 305 & 583 & 14.92 & 0.28 & 15.05 & \multicolumn{2}{|r|}{0.27} \\
\hline 310 & 583 & 11.75 & 0.27 & 11.94 & \multicolumn{2}{|r|}{0.25} \\
\hline 324 & 583 & 10.30 & 0.24 & 10.50 & \multicolumn{2}{|r|}{0.22} \\
\hline \multicolumn{7}{|c|}{ CORRECTION WITH SSA VARIABLE $(b=1.155)$} \\
\hline SSA variable & Slope & SE (Slope) & $\begin{array}{r}Y \text { intercept } \\
\left(\mathrm{mW} / \mathrm{m}^{2}\right)\end{array}$ & $\begin{array}{r}\mathrm{E}(Y \text { intercept }) \\
\left(\mathrm{mW} / \mathrm{m}^{2}\right)\end{array}$ & $R^{2}$ & $\operatorname{RMSE}(\%)$ \\
\hline UVER & 1.16 & 0.01 & -1.69 & 1.01 & 0.98 & 6.99 \\
\hline 305 & 1.16 & 0.01 & 0.12 & 0.26 & 0.98 & 8.23 \\
\hline 310 & 1.12 & 0.01 & 0.01 & 0.52 & 0.98 & 7.26 \\
\hline 324 & 1.08 & 0.01 & 5.50 & 2.70 & 0.96 & 6.39 \\
\hline SSA variable & $\mathrm{N}$ & $\operatorname{MBE}(\%)$ & $\mathrm{SE}(\mathrm{MBE})(\%)$ & $\operatorname{MABE}(\%)$ & SE $(\mathrm{M}$ & (ABE) $(\%)$ \\
\hline UVER & 583 & 11.65 & 0.26 & 11.85 & & 0.24 \\
\hline 305 & 583 & 13.34 & 0.29 & 13.58 & & 0.27 \\
\hline 310 & 583 & 10.08 & 0.27 & 10.44 & & 0.24 \\
\hline 324 & 583 & 8.73 & 0.24 & 9.08 & & 0.21 \\
\hline \multicolumn{7}{|c|}{ CORRECTION WITH SSA CONSTANT $(b=3.42)$} \\
\hline SSA constant & Slope & SE (Slope) & $\begin{array}{r}Y \text { intercept } \\
\left(\mathrm{mW} / \mathrm{m}^{2}\right)\end{array}$ & $\begin{array}{r}\mathrm{E}(Y \text { intercept }) \\
\left(\mathrm{mW} / \mathrm{m}^{2}\right)\end{array}$ & $R^{2}$ & $\operatorname{RMSE}(\%)$ \\
\hline UVER & 1.11 & 0.01 & -0.89 & 0.94 & 0.98 & 6.62 \\
\hline 305 & 1.11 & 0.01 & 0.23 & 0.24 & 0.98 & 7.78 \\
\hline 310 & 1.07 & 0.01 & 0.36 & 0.48 & 0.98 & 6.86 \\
\hline 324 & 1.04 & 0.01 & 7.79 & 2.52 & 0.96 & 6.10 \\
\hline SSA constant & $\mathrm{N}$ & $\operatorname{MBE}(\%)$ & $\mathrm{SE}(\mathrm{MBE})(\%)$ & $\operatorname{MABE}(\%)$ & $\mathrm{SE}(\mathrm{M}$ & MABE) $(\%)$ \\
\hline UVER & 583 & 8.40 & 0.25 & 8.91 & & 0.22 \\
\hline 305 & 583 & 10.01 & 0.28 & 10.50 & & 0.25 \\
\hline 310 & 583 & 6.90 & 0.26 & 7.71 & & 0.21 \\
\hline 324 & 583 & 6.30 & 0.23 & 6.98 & & 0.19 \\
\hline
\end{tabular}

a median overestimation of $0-10 \%$ for regions with modest loadings of absorbing aerosols. The OMI biases against reference Brewer data in El Arenosillo are inside this range when the correction for absorbing aerosols is applied (MBE values between 6-10\%). Therefore, our results can be considered as satisfactory, indicating the level of accuracy that may be reached by the OMI algorithm at the present status of research. Otherwise, ongoing investigations must be accomplished to better assess SSA values and hence to improve the estimated OMI values. 

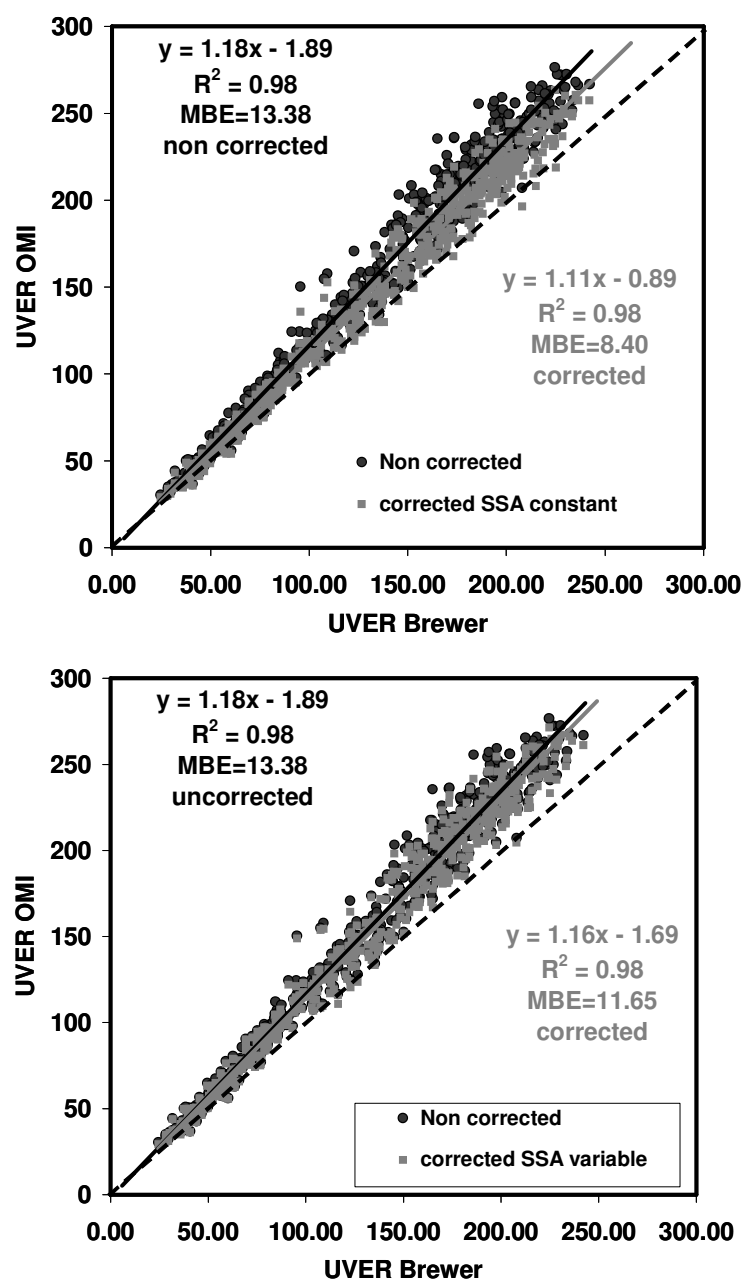

Fig. 10. Correlations and fits of OMI and Brewer irradiances without correction and for the two corrections: (a) first approach bases on SSA constant and (b) second approach based on SSA variable.

\section{Conclusions}

This work focuses on the influence of aerosols over the comparison between OMI and Brewer UV products at El Arenosillo station (South of Spain) for the period October 2004-December 2008. Under cloud-free conditions, our ground-based measurements overestimate the OMI data, around $13 \%$ for UVER and ranging from $10 \%$ to $15 \%$ for the spectral wavelengths, in agreement with other locations. When the aerosol corrections are applied, we find an OMI bias ranging from $6-10 \%$ for the SSA constant approach (from $13.4 \%$ to $8.4 \%$ for the UVER), which represents a relative reduction between $30 \%$ and $40 \%$ with respect to OMI bias without aerosol correction. For the SSA constant approach, the variation of AAOD depends only on AOD features. Less effective reduction is obtained when using available mean daily SSA values (form $13.4 \%$ to $11.6 \%$ for UVER), which in principle would appear as more reliable approach for aerosol correction.

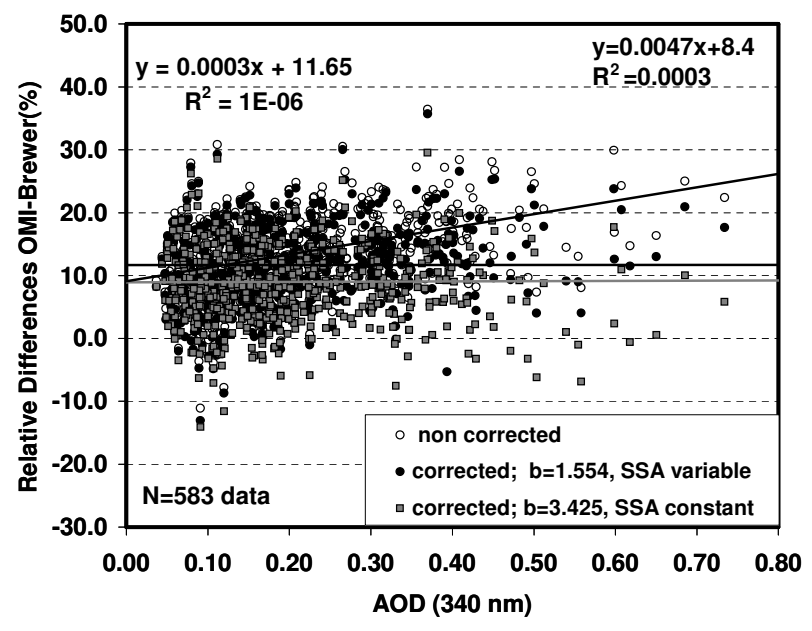

Fig. 11. Relative difference between OMI for UVER data as function of aerosol optical depth without correction when the two corrections are applied (a) for the first correction approach with SSA constant; (b) for the second correction approach with SSA variable. The number of data $(N)$ is specified inside the plot.

This inconsistent result may be related to the uncertain reliability of AERONET SSA level 1.5 of our data. Mainly due to the difficulty to determine absorbing aerosols in many sites a detailed analysis in our area of study has been performed, based on the available information of AOD-alpha parameters, more frequently available than AI and SSA. The analysis allows the selection of some defined aerosol groups, as polluted or desert dust types. However, some inconsistency related to this selection appeared. For instance, polluted aerosols based on AOD-alpha values appear as nonabsorbent according to AI values or moderate absorbing according to SSA values and also a few percent of data shows low values of SSA (very absorbing) in contrast with AI values lower than 0.5 (non-absorbing). Only desert dust data are in agreement for AOD-alpha, AI and SSA data. Most of the data of low $\operatorname{AOD}(440 \mathrm{~nm})$ values appear as non-absorbing according to AI with moderate SSA values, when the applied corrections work.

Proposed corrections for aerosol effect showed a relative high efficiency for reducing the OMI bias depending significantly on the slope of OMI/Brewer ratio over the absorption aerosol optical depth. Our results reflect the level of accuracy that may be reached in this type of comparison at present which may be considered as satisfactory. Nevertheless, improvements must be accomplished to determine reliable absorbing aerosol properties, which appear as the limiting factor to improve OMI bias.

Acknowledgements. The authors thank the OMI International Science Team for the satellite data used in this study and also to the teams of aerosol networks GSFC-NASA and PHOTONS. Also thanks to Antonio Serrano for his help in editing the manuscript. Manuel Antón thanks Ministerio de Ciencia e Innovación and 
Fondo Social Europeo for the award of a postdoctoral grant (Juan de la Cierva).This work has been partially supported by MICIN under coordinated project CGL2008-05939-C03/CLI of UVA-INTA-UNEX. Also this work is financed by GR220 project of "Junta de Castilla y León".

Edited by: W. Lahoz

\section{References}

Antón, M., Cachorro, V. E. , Vilaplana, J. M.,. Krotkov, N. A, Serrano, A., Toledano, C., de la Morena, B., and Herman, J. R.: Total ozone mapping spectrometer retrievals of noon erythemalCIE ultraviolet irradiance compared with Brewer ground-based measurements at El Arenosillo (southwestern Spain), J. Geophys. Res., 112, D11206, doi:10.1029/2006JD007254, 2007.

Antón, M., Cachorro, V. E., Vilaplana, J. M., Toledano, C., Krotkov, N. A., Arola, A., Serrano, A., and de la Morena, B.: Comparison of UV irradiances from Aura/Ozone Monitoring Instrument (OMI) with Brewer measurements at El Arenosillo (Spain) - Part 1: Analysis of parameter influence, Atmos. Chem. Phys., 10, 5979-5989, doi:10.5194/acp-10-5979-2010, 2010.

Arola, A., Kazadzis, S., Krotkov, N., Bais, A., Gröbner, J., and Herman, J. R.: Assessment of TOMS UV bias due to absorbing aerosols, J. Geophys. Res., 110, D23211, doi:10.1029/2005JD005913, 2005.

Arola, A., Kazadzis, S., Lindfors, A., Krotkov, N. A., Kujanpä, J., and Tamminen, J.: A new approach to correct for absorbing aerosols in OMI UV, Geophys. Res. Lett., 36, L22805, doi:10.1029/2009GL0411137, 2009.

Buchard, V., Brogniez, C., Auriol, F., Bonnel, B., Lenoble, J., Tanskanen, A., Bojkov, B., and Veefkind, P.: Comparison of OMI ozone and UV irradiance data with ground-based measurements at two French sites, Atmos. Chem. Phys., 8, 4517-4528, doi:10.5194/acp-8-4517-2008, 2008.

Cachorro, V. E., De Frutos, A. M., and J. L. Casanova: Determination of Ångström turbidity parameters, Appl. Optics, 26, 30693076, 1987.

Cachorro, V. E., Vergaz, R., Martin, M. J., de Frutos, A. M., Vilaplana, J. M., and de la Morena, B.: Measurements and estimation of the columnar optical depth of tropospheric aerosols in the UV spectral region, Ann. Geophys., 20, 565-574, doi:10.5194/angeo-20-565-2002, 2002.

Cachorro, V. E., Vergaz, R., de Frutos, A. M., Vilaplana, J. M., Henriques, D., Laulainen, N., and Toledano, C.: Study of desert dust events over the southwestern Iberian Peninsula in year 2000: two case studies, Ann. Geophys., 24, 1493-1510, doi:10.5194/angeo-24-1493-2006, 2006.

Cachorro, V. E., Toledano, C. , Prats, N., Sorribas, M., Mogo, S., Berjón, A., Torres, B.,. Rodrigo, R, de Frutos, A. M., and de la Rosa, J.: The strongest desert dust intrusion mixed with smoke over the Iberian Peninsula registered with sun-photometry, J. Geophys. Res., 113, D14504, doi:10.1029/2007JD009582, 2008.

Cachorro, V. E., Berjon, A., Toledano, C., Mogo, S., Prats, N., de Frutos, A. M., Vilaplana, J. M., Gröbner, J., and Naulainen, N.: Detailed Diurnal Aerosol Optical Depth intercomparison between Brewer, Licor1800 spectroradiometer and Cimel sun-photometer during various short inten- sive campaigns, J. Atmos. Ocean. Tech., 26, 1558-1571, doi:10.1175/2009JTECHA1217.1, 2009.

Dubovik, O. and King, M. D.: A flexible inversion algorithm for retrieval of aerosol optical properties from Sun and sky radiance measurements, J. Geophys. Res., 105, 20673-20696, 2000.

Dubovik, O., Holben, B. N., Eck, T. F., Smirnov, A., Kaufman, Y. J., King, M. D., Tanré, D., and Slutsker, I.: Variability of absorption and optical properties of key aerosol types observed in woldwide locations, J. Atmos. Sci., 59, 590-608, 2002.

Eck, T. F., Holben, B. N., Reid, J. S., Dubovik, O., Smirnov, A., O'Neil N. O., Slutsker, I., and Kinne, S.: Wavelength dependence of the optical depth of biomass burning, urban, and desert dust aerosols, J. Geophys. Res., 106, 31333-31349, 1999.

Gonzalez-Castanedo, Y.: Caracterización geoquimica y contribución de fuentes de material particulado atmosférico en El Arenosillo, SW de la Peninsula Ibérica, PhD Degree, University of Huelva, 2007.

Gröbner J. and Meleti, C.: Aerosol optical depth in the UVB and visible from Brewer spectrophotometer direct irradiance measurements: 1991 to 2002, J. Geophys. Res., 109(D9), D09202, doi:2003JD004409, 2004.

Gröbner, J., Vergaz, R., Cachorro, V., Henriques, D., . Lamb, K., Redondas, A., Vilaplana, J., and Rembges, D., Intercomparison of aerosol optical depth measurements in the UVB using Brewer spectrophotometers and a Li-Cor spectrophotometer, Geophys. Res. Lett., 28(9), 1691-1694, 2001.

Hsu, N. C., Herman, J. R., Torres, O., Holben, B., Tanre, D., Eck, T. F., Smirnov, A., Chatenet, B., and Lavenu, F.: Comparison of the TOMS aerosol index with sun photometer aerosol optical thickness: results and applications, J. Geophys. Res., 104, 62696279, 1999.

Ialongo, I., Casale, G. R., and Siani, A. M.: Comparison of total ozone and erythemal UV data from OMI with ground-based measurements at Rome station, Atmos. Chem. Phys., 8, 32833289, doi:10.5194/acp-8-3283-2008, 2008.

Ialongo, I., Buchard, V., Brogniez, C., Casale, G. R., and Siani, A. M.: Aerosol Single Scattering Albedo retrieval in the UV range: an application to OMI satellite validation, Atmos. Chem. Phys., 10, 331-340, doi:10.5194/acp-10-331-2010, 2010.

Kalliskota, S., Kaurola, J., Taalas P., Herman, J., Celarier, E., and Krotkov, N.: Comparison of daily UV doses estimated from Nimbus 7/TOMS measurements and ground-based spectroradiometer data, J. Geophys. Res., 105, 4273-4277, 2000.

Kazantzidis, A., Bais, A. F., Grobner, J., Herman, J. R., Kazadzis, S., Krotkov, N., Kyrö, E., den Outer, P. N., Garane, K., Görts, P., Lakkala, K., Meleti, C., Slaper, H., Tax, R. B., and Turunen, T.: Comparison of satellite-derived UV irradiances with groundbased measurements at four European stations, J. Geophys. Res., 111, D13207, doi:10.1029/2005JD006672, 2006.

Kazadzis, S., Bais, A., Kouremeti, N., Garasopoulos, E., Garane, K., Blumthaler, M., Schallhart, B., and Cede, A.: Direct spectral measurements with a Brewer spectroradiometer: absolute calibration and aerosol optical depth retrieval, Appl. Opt., 44, 16811690, 2005.

Kazadzis, S., Bais, A., Amiridis, V., Balis, D., Meleti, C., Kouremeti, N., Zerefos, C. S., Rapsomanikis, S., Petrakakis, M., Kelesis, A., Tzoumaka, P., and Kelektsoglou, K.: Nine years of UV aerosol optical depth measurements at Thessaloniki, Greece, Atmos. Chem. Phys., 7, 2091-2101, doi:10.5194/acp-7-2091- 
2007, 2007.

Kazadzis, S., Bais, A., Arola, A., Krotkov, N., Kouremeti, N., and Meleti, C.: Ozone Monitoring Instrument spectral UV irradiance products: comparison with ground based measurements at an urban environment, Atmos. Chem. Phys., 9, 585-594, doi:10.5194/acp-9-585-2009, 2009.

Krotkov, N. A., Barthia, P. K., Herman, J. R., Fioletov, V., and Kerr, J.: Satellite estimation of spectral surface UV irradiance in the presence of tropospheric aerosols 1. clod free cases, J. Geophys. Res., 103, 8779-8793, 1998.

Krotkov, N. A., Herman, J., Barthia, P. K., Seftor, C., Arola, A., Kaurola, J., Taalas, P., and Vasilkov, A.: Clouds, Aerosols, and Surface UV Irradiance, in OMI Algorithm Theoretical Basis Document, vol. III, ATBD-OMI-03, edited by P. Stammes, pp. 72-109, NASA Goddard Space Flight Cent., Greenbelt, Md., available at: http://www.knmi.com/omi/documents/data/ OMI_ATBD_Volume_3_V2.pdf, 2002.

Krotkov, N. A., Barthia P. K., Herman J. R., Slusser J., Scott G., Labow G., Vasilkov A. P., Eck T. F., Dubovik O., and Holben, B. N.: Aerosol ultraviolet absorption experiment (2000 to 2004), part 2: Absorption optical thickness, refractive index, and single scattering albedo, Opt. Eng., 44(4), 041005, doi:10.1117/1.1886819, 2005.

Krotkov, N., Labow, G., Herman, J., Slusser, J., Tree, R., Jason, G., Durham, B., Eck, T., and Holben, B.: Aerosol column absorption measurements using co-located UV-MFRSR and AERONET CIMEL instruments, in: Ultraviolet Ground- and Space-based Measurements, Models, and Effects VI, edited by: Herman, J. R. and Wei, G., Proceedings of SPIE, 7462, SPIE, Bellingham, WA, 2009.

Marenco, F., di Sarra, A., and de Luisi, J.: Methodology for determining aerosol optical depth from Brewer 300-320 nm measurements, Appl. Opt., 41, 1805-1814, 2002.

McKinlay, A. F. and Diffey, B. L.: A reference spectrum for ultraviolet induced erythema in human skin, CIE-J., 6, 21-27, 1987.

Meloni, D., di Sarra A., DeLuisi, J., Di Iorio, T., Fiocco, G., Junkermann, W., and Pace, G.: Tropospheric aerosols in the Mediterranean: 2. Radiative effects through model simulations and measurements, J. Geophys. Res., 108(D10), 4317, doi:10.1029/2002JD002807, 2003.

Ortiz de Galisteo, J. P., Toledano, C., Rodriguez, E., Cachorro, V. E., and de Frutos, A. M.: Analysis of Aerosol Optical Depth Evaluation in Polar Regions and Associated uncertainties, Adv. Sci. Res., 2, 5-8, 2008.

Pére, J. C., Mallet, M., Bessagnet, B., and Pont, V.: Evidence of the aerosol core-shell mixing state over Europe during the heat wave of summer 2003 by using CHIMERE simulations and AERONET inversions, Geophys. Res. Lett., 36, L09807, doi:10.1029/2009GL037334, 2009.
Prats, N.: Utilización del fotómetro Cimel (AERONET) para el análisis de parámetros microfísicos y radiativos del aerosol atmosférico en el suroeste de la Península Ibérica, PhD Dissertation, Universidad de Valladolid (Spain), 2009.

Prats, N., Cachorro, V. E., Sorribas, M., Toledano, C., Berjón, A., Rodrigo, R., Torres B., and de Frutos, A. M.: Analysis of AERONET inversion algorithm's products at "El Arenosillo" station, southwest Spain, International Radiation Symposium (IRS2008), Foz do Iguaçu, Brazil, 2008.

Tanskanen, A., Lindfors, A., Maatta, A., Krotkov, N., Herman, J., Kaurola, J., Koskela, T., Lakkala, K., Fioletov, V., Bernhard, J., McHenzie, R., Kondo, Y., O’Neill, M., Slaper, H., den Outer, P., Bais, A. F., and Tamminen, J.: Validation of daily erythemal doses from OMI with ground-based UV measurement data, J. Geophys. Res., 112, D24S44, doi:10.1029/2007JD008830, 2007.

Toledano, C., Cachorro, V. E., Sorribas, M., Berjón, A., de la Morena, B. A., de Frutos, A. M., and Gouloub, P.: Aerosol optical depth and Ångström exponent climatology at 'El Arenosillo' AERONET site (Huelva, Spain), Q. J. Roy. Meteorol. Soc., 133, 795-807, doi:10.1002/qj.54, 2007a.

Toledano, C., Cachorro, V. E, de Frutos, A. M., Sorribas, M., Prats, N., and de la Morena, B.: Inventory of African desert dust events over the southwestern Iberian Peninsula in 2000-2005 with an AERONET Cimel Sun photometer, J. Geophys. Res., 112, D21201, doi:10.1029/2006JD008307, 2007b.

Toledano, C., Cachorro, V. E., de Frutos, A. M., Torres, B., Sorribas, M., and Stone, R.: Air masses classification and analysis of aerosol types at El Arenosillo (Spain), J. Appl. Meteorol., 48(5), 962-981, doi:10.1175/2008JAM2006.1, 2009.

Torres, O. and Barthia, P. K.: Impact of tropospheric aerosol absorption on ozone retrieval from backscattered ultraviolet measurements, J. Geophys. Res., 104, 21569-21577, 1999.

Torres, O., Tanskanen, A., Veihelmann, B., Ahn, C., Braak, R., Bhartia, P. K., Veefkind, P., and Levelt, P.: Aerosols and surface UV products from Ozone Monitoring Instrument observations: An overview, J. Geophys. Res., 112, D24S47, doi:10.1029/2007JD008809, 2007.

Weihs, P., Blumthaler, M., Rieder, H. E., Kreuter, A., Simic, S., Laube, W., Schmalwieser, A. W., Wagner, J. E., and Tanskanen, A.: Measurements of UV irradiance within the area of one satellite pixel, Atmos. Chem. Phys., 8, 5615-5626, doi:10.5194/acp8-5615-2008, 2008. 